\title{
Blocked goals, persistent action: Implementation intentions engender tenacious goal striving
}

Citation for published version (APA):

Martijn, C., Alberts, H. J. E. M., Sheeran, P., Peters, G. J., Mikolajczak, J., \& de Vries, N. K. (2008).

Blocked goals, persistent action: Implementation intentions engender tenacious goal striving. Journal of Experimental Social Psychology, 44, 1137-1143. https://doi.org/10.1016/j.jesp.2008.01.005

Document status and date:

Published: 01/01/2008

DOI:

10.1016/j.jesp.2008.01.005

Document Version:

Publisher's PDF, also known as Version of record

Document license:

Taverne

Please check the document version of this publication:

- A submitted manuscript is the version of the article upon submission and before peer-review. There can be important differences between the submitted version and the official published version of record.

People interested in the research are advised to contact the author for the final version of the publication, or visit the DOI to the publisher's website.

- The final author version and the galley proof are versions of the publication after peer review.

- The final published version features the final layout of the paper including the volume, issue and page numbers.

Link to publication

\footnotetext{
General rights rights.

- You may freely distribute the URL identifying the publication in the public portal. please follow below link for the End User Agreement:

www.umlib.nl/taverne-license

Take down policy

If you believe that this document breaches copyright please contact us at:

repository@maastrichtuniversity.nl

providing details and we will investigate your claim.
}

Copyright and moral rights for the publications made accessible in the public portal are retained by the authors and/or other copyright owners and it is a condition of accessing publications that users recognise and abide by the legal requirements associated with these

- Users may download and print one copy of any publication from the public portal for the purpose of private study or research.

- You may not further distribute the material or use it for any profit-making activity or commercial gain

If the publication is distributed under the terms of Article $25 \mathrm{fa}$ of the Dutch Copyright Act, indicated by the "Taverne" license above, 


\title{
Blocked goals, persistent action: Implementation intentions engender tenacious goal striving is
}

\author{
Carolien Martijn ${ }^{\mathrm{a}, *}$, Hugo Alberts ${ }^{\mathrm{a}}$, Paschal Sheeran ${ }^{\mathrm{b}}$, Gjalt-Jorn Y. Peters ${ }^{\mathrm{c}}$, \\ Jochen Mikolajczak $^{\mathrm{c}}$, Nanne K. de Vries ${ }^{\mathrm{d}}$ \\ ${ }^{a}$ Department of Clinical Psychological Science, Faculty of Psychology, Universiteit Maastricht, P.O. Box 616, 6200 Maastricht, MD, The Netherlands \\ ${ }^{\mathrm{b}}$ Department of Psychology, University of Sheffield, United Kingdom \\ ${ }^{\mathrm{c}}$ Department of Work and Social Psychology, Faculty of Psychology, Universiteit Maastricht, The Netherlands \\ ${ }^{\mathrm{d}}$ Department of Health Education and Promotion, Faculty of Health, Medicine and Life Sciences, Universiteit Maastricht, The Netherlands
}

Received 21 August 2007

Available online 12 February 2008

\begin{abstract}
Research on goal attainment has demonstrated that people are more likely to reach their goals when they form implementation intentions. Three experiments tested whether implementation intentions lead to tenacious goal striving following blockage of an initial attempt to reach the goal. In all three experiments some participants were instructed to form an implementation intention and other participants were not. Subsequently, the initial goal-directed attempt of all participants was unexpectedly blocked. Experiment 1 found that implementation intentions resulted in more attempts to realize one's goal. Experiment 2 showed that when participants formed an implementation intention their repeated attempt was acted out as intensely as their first, blocked attempt. Experiment 3 found that implementation intentions still allow people to seize an alternative, more onerous means to realize their intention. These results imply that implementation intention conserve self-regulatory strength. After goal blockage, the remaining strength can be used to continue goal-directed action. (c) 2008 Elsevier Inc. All rights reserved.
\end{abstract}

Keywords: Implementation intentions; Goals; Goal blockage; Self-regulation; Persistence; Internet

A variety of factors have been documented to explain why people fail to act upon their good intentions including past behavior and habits (e.g., Aarts \& Dijksterhuis, 2000; Ouellette \& Wood, 1998; Triandis, 1980), social context (Gibbons, Gerrard, Blanton, \& Russell, 1998), or intention certainty (e.g., Bagozzi \& Yi, 1989; Sheeran, 2002). A relatively understudied factor that contributes to the intentionbehavior gap is the role of unforeseen barriers, i.e. factors

\footnotetext{
This work was supported by Grants of the Netherlands Organization for Scientific Research (NWO, Grant No. 402-01-049) and of the Netherlands Organization for Health Research (ZonMw, Grant No. 401-60-001). We thank Roy Strüver, Marten van de Braak and Saman Maroofi for their help with collecting the data and Bram Amendt for his advice on programming the website.

* Corresponding author.

E-mail address: c.martijn@psychology.unimaas.nl (C. Martijn).
}

that prevent goal attainment and that were not anticipated at the time the intention was formulated (DiBonaventura \& Chapman, 2005; Sheeran, Trafimow, \& Armitage, 2003). In the present article, we examine whether forming implementation intentions may help people to deal effectively with such unforeseen barriers.

Implementation intentions (Gollwitzer, 1993, 1999; Gollwitzer \& Sheeran, 2006) are if-then plans that specify the when, where, and how of goal striving in advance. The essential difference between goal intentions and implementation intentions is that goal intentions merely specify what one wants to achieve ("I intend to reach $Z$ !") whereas implementation intentions specify what behavior one will perform to reach the goal and in what situation one will perform it in a contingent format ("If situation $Y$ occurs, then I will initiate behavior $X$ in order to obtain outcome $Z$ !"). Implementation intention formation thus entails not 
merely being specific about the goal-directed behavior and situation in which it will be initiated, but also involves making performance of the behavior conditional upon encountering that situation. For instance, Oettingen, Hönig, and Gollwitzer (2000, Study 3) showed that participants who formed a specific goal intention ("I will perform as many arithmetic tasks as possible on Wednesday at [selfchosen time]!") were much less likely to achieve their goal compared to participants who formed an implementation intention that was equally specific (in terms of the respective goal or action) but had a contingent format ("If it is Wednesday at [self-chosen time], then I will perform as many arithmetic tasks as possible!") (see Chapman, Armitage, \& Norman, in press, for equivalent findings). Thus, implementation intentions can be designated if-then plans (rather than, e.g., 'specific goals' or 'action plans') because contingencies are set up between specific situations and specific actions.

The consequence of selecting a good opportunity to act and a good action to perform, and making action initiation contingent upon encountering the specified opportunity is that (a) the anticipated opportunity becomes highly accessible, and (b) a strong mental link is forged between the situation and goal-directed response. These processes in turn make it likely that people indeed act as planned when the situation occurs (Aarts, Dijksterhuis, \& Midden, 1999; Webb \& Sheeran, 2007). The moment the relevant situation is encountered, goal-directed behavior can be started at once, without wasting time or expending cognitive resources (Gollwitzer \& Sheeran, 2006). Implementation intentions can thus be regarded as "instant" habits because they result from a deliberate attempt to automatize future behavior (Gollwitzer \& Schaal, 1998).

In this contribution we focus on the strength of implementation intention effects when people unexpectedly run up against barriers. The issue is whether implementation intention formation (as compared to forming goal intentions) not only facilitates the initiation of goal striving but also promotes continued striving when the initial attempt to reach the goal is blocked. The present research is novel in two respects. First, although numerous studies have shown implementation intention effects on the initiation of goal striving, less research has examined effects on repeated strivings (Gollwitzer \& Sheeran, 2006), and, to date, no studies appear to have tested whether if-then planning affects subsequent goal striving when the path to the goal is blocked.

Second, and more important, we examine whether an implementation intention that is geared solely towards the initiation of goal striving - and does not specify the when, where, or how of continued attempts to reach the goal - can still enhance subsequent goal striving. Participants are asked only to specify the situational cue for initiating action (the date, time, and place they will act), and their route to the goal is then unexpectedly blocked. Unlike initial goal striving, subsequent strivings are not directly controlled by implementation intentions because (a) the original situational cue no longer holds (the specified date has passed), and (b) participants have formed no if-then plan that spells out how they should proceed in the wake of the unforeseen barrier to goal attainment. The odds therefore seem stacked against improved goal striving among participants who form implementation intentions compared to participants who merely formed goal intentions. Nonetheless, we predict such improvement-based on evidence that implementation intentions conserve selfregulatory capacity (Gollwitzer \& Sheeran, 2006; Webb \& Sheeran, 2003). The idea is that when initial striving is controlled by goal intentions, this uses up self-regulatory resources and so fewer resources are available for subsequent goal striving (i.e., people become ego depleted by their initial exertions; Baumeister, Bratslavsky, Muraven, \& Tice, 1998; reviews by Muraven \& Baumeister, 2000; Schmeichel \& Baumeister, 2004). Forming an implementation intention, on the other hand, automatizes initial goal striving and thus conserves self-regulatory resources that can later be used in making successive efforts to reach the goal.

This idea is explored in three studies. The studies all used the same basic design. One-half of participants expressed the strength of their intention to obtain a certain goal, whereas the other half additionally formed an implementation intention. Subsequently, all participants were impeded during their initial attempts and did not reach the goal. The prediction tested is that if-then planners will be more likely not only to initiate goal striving but also to continue striving when their initial attempt is blocked compared to participants who form goal intentions. To provide a comprehensive test of respective implementation intention effects, we examine three different features of subsequent goal striving. Experiment 1 tests whether forming an implementation intention fosters tenacious goal striving (i.e., repeated efforts to attain the focal goal). We predict that participants who form implementation intentions will be more likely to repeat a goaldirected action compared to goal intention participants. Experiment 2 focuses on the quality of subsequent goal striving. We predict that, for goal intention participants, the quality of repeated goal-directed action will decline in the wake of blockage whereas no such decline will be observed among if-then planners. Experiment 3 assesses whether participants who form implementation intentions are receptive to an alternative but highly demanding means of attaining a goal when their initial efforts are blocked. Previous research has shown that forming ifthen plans does not engender insensitivity to new, more effective routes to goal attainment-so long as participants receive feedback that the new response produces better outcomes than the original planned response (Gollwitzer, Jaudas, Parks, \& Sheeran, 2008). Our prediction is that implementation intention participants will be more likely to use an alternative behavioral means that is highly demanding of self-regulatory resources compared to goal intention participants. 
Experiment 1: Making repeated attempts to reach one's goal

\section{Method}

Participants and design. A total of 131 first year psychology students (85 women) of the Universiteit Maastricht voluntarily participated in our study. Participants were randomly assigned to a goal intention or an implementation intention condition.

Procedure. At the end of a first year lecture, students were asked to participate in a short internet study that would take 5-10 min of their time. They were invited to visit a certain website during the next 2 weeks in order to gain access to an on-line questionnaire. It was explained that each website visitor would have a chance of winning one of three 50 Euro gift vouchers. Subsequently, the lecturer and three research assistants distributed one-page questionnaires. The experimental manipulation was embedded in the questionnaire completed by participants. Both questionnaires started with a brief recapitulation of the instructions and the address of the website. Students were requested to rate the strength of their goal intention to visit the website ("Please indicate on the following scale to what extent you intend to surf to the webpage and to fill out the on-line questionnaire. Please circle the number that matches your answer"). Answers were gathered on a 5point scale ranging from 1 (certainly will not) to 5 (certainly will). Next, students had to provide their name and e-mail address if they circled a 3,4 or 5 on the goal intention scale ("then we know where to reach you if you win a prize!"). At this point, the questionnaire ended for students in the goal intention condition. The questionnaire for the implementation intention condition continued with the following additional text: "It is more likely that you will visit the website and fill out our questionnaire if you decide now when and where you will do this. Please indicate this below." The form continued with the prompts "When...?", "Where. ..?" and "...Then what you will do...?", each followed by a dashed line on which participants could write down their answers. In this way the action (the then-component, i.e., visiting the website) was conditional upon the "when" and "where" (the if-component, i.e., a self-chosen situation for acting). Thus, the plan had the critical contingent format for implementation intentions (cf. Oettingen et al., 2000).

Website. When participants typed in the name of the website an interactive page appeared on which they had to enter their first and last name. Their names were recorded in a data file together with the exact date and time of their web visit. Then participants received the following message on their computer screen: "Sorry, because of server problems the site is temporarily out of order. We are working on it. The questionnaire will be on-line as soon as possible. Please try again later." This procedure was repeated for each subsequent visit to the website (registration of names, and exact time of visit followed by the same error message).
Dependent variable. The number of times participants that visited the website formed the dependent variable.

\section{Results}

A total of 134 forms were handed in at the end of the lecture. Forms of three students were discarded because they indicated a weak intention to visit the website (scores of 1 or 2 on the intention strength scale). Data from the remaining 131 participants (goal intention: $n=76$, implementation intention, $n=55$ ) were subjected to further analyzes. A one-way analysis of variance showed that the goal intention condition and the implementation intention condition did not differ with respect to their intention to visit the website ( $M_{\text {goal intention }}=4.32$, $\left.S D=.77 ; \quad M_{\text {implementation intention }}=4.44, \quad S D=.63\right), \quad F(1$, $129)<1$, ns. In the goal intention condition, $40.8 \%$ $(n=31)$ of the participants visited the website at least once whereas $65.5 \%(n=36)$ of the participants in the implementation intention condition visited the website, $\chi^{2}(1$, $N=131)=7.77, p<.01$. The correlation between the number of website visits and intention was $.11(n s)$ in the goal intention condition and .28 $(p<.05)$ in the implementation intention condition. Table 1 provides an overview of number and percentage of website visits per condition.

To test whether implementation intention participants returned more often to the website than goal intention participants, subsequent analyzes concerned only those participants who paid the website at least one visit ( $n=67,51.1 \%$ of total sample). Of the 31 participants who formed a goal-intention and visited the website at least once, $29 \%(n=9)$ visited the website two times or more and $71 \%(n=22)$ visited the website only once. With respect to 36 implementation intention participants who visited the website at least once, the proportion was exactly the other way around; $69.4 \%(n=25)$ visited the website twice or more whereas $30.6 \%(n=11)$ did not return after one visit. This difference in proportion of "one-time visitors" and "returning visitors" per condition was significant, $\chi^{2}(1, N=67)=10.88, p<.01$. Overall, participants who formed an implementation visited our website more often than did goal intention participants $\left(M_{\text {implementation intention }}=2.66, S D=1.81 ; \quad M_{\text {goal intention }}=\right.$ $1.63, S D=1.05), t(66)=3.46, p=.001$.

Table 1

Number of web visits of goal intention participants and implementation intention participants

\begin{tabular}{lcc}
\hline Type of response & $\begin{array}{c}\text { Goal intention } \\
n(\%)\end{array}$ & $\begin{array}{c}\text { Implementation intention } \\
n(\%)\end{array}$ \\
\hline No visit & $45(59.2)$ & $19(34.5)$ \\
1 Web visit & $22(28.9)$ & $11(20.0)$ \\
2 Web visits or more & $9(11.8)$ & $25(45.5)$ \\
Total & $76(100)$ & $55(100)$ \\
\hline
\end{tabular}




\section{Discussion}

Experiment 1 showed that despite expressing an equally strong intention to visit a website and fill out an on-line questionnaire, participants who formed an implementation intention were more likely to actually visit the website than were participants who formed goal intentions. This result replicates earlier findings (see Gollwitzer \& Sheeran, 2006) concerning the impact of implementation intention formation on action initiation. A novel finding is that when a first attempt to open the webpage failed, participants who formed an implementation intention revisited the website more often compared to participants who did not form an if-then plan. In other words, our results suggest that implementation intentions engender greater tenacity whereas people without an if-then plan tend to give up sooner when confronted with an unforeseen barrier.

Experiment 2 was designed to further examine the characteristics of persistent behavior. More specifically, we examine the quality of participants' second try at reaching the goal (as compared to their initial attempt) to see whether forming implementation intentions helps to maintain the caliber of goal striving.

\section{Experiment 2: Maintaining the quality of attempts to reach one's goal}

\section{Method}

Participants and procedure. At the end of a second year health science lecture, we asked students to participate in a small internet study that was presented as a survey on "study experiences of health science students." The cover story and procedure were similar to that used in Experiment 1. After a short oral explanation, all participants received a form on which they expressed the strength of their intention (goal intention condition), or also specified where and when they intended to visit the website (implementation intention condition).

Website. When participants visited the website they entered their first and last name. This time, the website worked and the "study experiences" questionnaire appeared on the screen. The questionnaire consisted of eight open-ended questions and encouraged elaborate answers. When participants finished answering all the eight questions they were requested to click on the "submit" button in order to submit the questionnaire to the researchers. If a participant did so, the answers were recorded. The participant, however, received an error message on the screen immediately after submitting their answers ("Warning: file(questions.html):failed to open stream: write error in directory ..." etc.). Beneath the error message the following text appeared: "An unexpected error occurred. Your submission failed. Click on "try again" to fill out the questionnaire again." When the participants filled out the questionnaire for a second time and submitted their answers, they received a message that their submission was success- ful. The answers on the second attempt were again recorded.

Dependent variables. We recorded whether a participant visited the website and the number of words he or she used at the first attempt and the second attempt to answer the questionnaire. The main dependent variable was the difference in number of words used in the first versus the second questionnaire.

\section{Results}

Eighty-eight students returned their completed forms (goal intention $n=41$; implementation intention $n=47$ ). All students indicated that they intended to visit the website within the next 2 weeks (intention strength score $>2$ ).

There was no difference in strength of intention between conditions $\left(M_{\text {goalintention }}=4.03, \quad S D=1.07\right.$; $\left.M_{\text {implementation intention }}=4.11, \quad S D=.70\right), \quad t(85)<1, \quad n s$. Again, the basic effect of type of intention on initiation of goal striving was replicated; the proportion of web visitors with an implementation intention (28 out of $47=59.6 \%$ ) was greater than the proportion of web visitors with a mere goal intention $(15$ out of $41=36.6 \%)$, $\chi^{2}(2, N=88)=4.63, p<.05$.

Next, we selected only those participants visited the website and made a first attempt to fill out the questionnaire. We then checked for possible differences between conditions for participants who did and did not engage in a second attempt. In both the goal intention condition and the implementation intention about $60 \%$ of the participants made a second attempt to fill out the questionnaire. In the implementation intention condition 17 out of 28 participants $(60.7 \%)$ made a second attempt whereas 9 out of 15 participants $(60 \%)$ in the goal intention condition did so.

The number of words used for the first and second questionnaires was entered in a 2-between (Type of Intention: goal vs. implementation intention) $\times 2$-within (Attempt: first vs. second) ANOVA. The analysis revealed a main effect of Attempt, $F(1,24)=11.91, p<.01$ indicating that, overall, participants used more words at their first than at their second attempt to complete the questionnaire $\left(M_{\text {first attempt }}=159.1, \quad S D=75.5 ; \quad M_{\text {second attempt }}=132.0\right.$, $S D=49.1)$. This main effect was, however, qualified by the interaction between Type of Intention and Attempt, $F(1,24)=3.63, p<.05$ (see Table 2). Simple $t$-tests revealed that in the implementation intention condition the number of words used at the first and second attempt was about equal, $t(16)=1.47, p=.18$. In the goal intention condition participants used less words on their second compared to their first attempt, $t(8)=3.24, p=.012$. Another way of describing the Type of Intention $\times$ Attempt interaction is that participants in the goal intention condition and the implementation condition used about the same amount of words at their first attempt to complete the questionnaire, $t(24)=.10, p=.92$. However, at the second attempt participants who formed implemen- 
Table 2

Mean and standard deviation of words used at the first and second attempt to answer the questionnaire by condition of participants who took part in both attempts

\begin{tabular}{lcc}
\hline Response & $\begin{array}{c}\text { Goal intention } \\
m(S D)\end{array}$ & $\begin{array}{c}\text { Implementation } \\
\text { intention } m(S D)\end{array}$ \\
\hline Words at 1st questionnaire attempt & $158.5(54.04)$ & $161.24(69.45)$ \\
Words at 2nd questionnaire attempt & $108.4(31.02)$ & $144.4(53.0)$ \\
Difference & $47.4(46.62)$ & $15.5(47.48)$ \\
\hline
\end{tabular}

tation intentions used more words than participants who merely expressed a goal intention, $t(24)=2.11, p=.048$.

\section{Discussion}

Experiment 2 demonstrated that when a first attempt to reach a goal is blocked but participants immediately are offered an opportunity to try again (unlike Experiment 1 ), about an equal proportion of goal intention and implementation intention participants engaged in a second attempt. The difference between the two intention conditions became apparent when we compared the number of words that were used in both conditions (i.e., quality of goal striving). The finding that implementation intention participants used about the same number of words in their second attempt as in their first, whereas the answers from goal intention participants much shorter, indicates that goal blockage does not lead to a loss of quality of goaldirected behavior when people specified an if-then plan beforehand.

In Experiment 3 we explore the tenacity of goal striving engendered by implementation intention formation further by examining whether planning makes it more likely that participants will adopt alternative, effortful means of attaining their goal when confronted with an unexpected barrier.

\section{Experiment 3: Seizing alternative means to reach one's goal}

\section{Method}

Participants and procedure. Questionnaires identical to those used in Experiments 1 and 2 were distributed at the end of a lecture for second year psychology students. Students either indicated the strength of their intention (goal intention condition, $n=51$ ) or additionally specified where and when they intended to visit our website (implementation intention condition, $n=51$ ).

Website. When students typed in the name of the website, an interactive page appeared on which they entered their first and last name. Participants' names were recorded in a data file together with the date and time of their web visit. Then students received the following message on their computer screen: "Sorry, because of server problems the site is temporarily out of order. We are working on it. The ques- tionnaire will be on-line as soon as possible. Please try again later. Another possibility is that you try another website and download the questionnaire yourself. Please go to: (address of alternative website). After you have downloaded the questionnaire, please fill it out and send it to: (e-mail address). In this way, we suggested to visitors an alternative means to reach their goal (filling out the online questionnaire). However, the alternative procedure was deliberately more complicated. To reach their goal, participants had to perform the following, more time-consuming sequence of behaviors:

(1) visit another website, (2) download the questionnaire, (2) fill it out, (3) save it to their computer, (4) open their e-mail editor, and (5) send it to our e-mail address. ${ }^{1}$

Dependent variables. The first dependent variable was whether participants visited the website. Whether or not participants sent an e-mail formed the second dependent variable.

\section{Results and discussion}

There was no difference in strength of intention between participants in the goal intention condition $(M=4.12$, $S D=.68)$ and the implementation intention condition $(M=3.92, S D=.82), t(101)=1.12, n s$. In the goal intention condition, $35.3 \%(n=18)$ of the participants visited the website at least once, whereas $60.8 \%(n=31)$ of the participants in the implementation intention condition visited the website. The difference in the proportion of visitors and non-visitors by condition was significant, $\chi^{2}(1$, $N=102)=6.64, p<.01 .^{2}$

Next, we selected those participants who visited the website at least once and checked for differences between conditions in the proportion of participants who used the more laborious, alternative means to reach the goal (the e-mail procedure). Of the visitors in the goal-intention condition,

\footnotetext{
${ }^{1}$ The perceived laboriousness of the two goal-directed actions ("try again later" and "go to another website") were examined in a pilot study $(n=19)$. The two options were described fully in a questionnaire and participants were asked to rate the extent to which each option would demand their time and effort $(1=$ not at all time-consuming to $9=$ very time-consuming, and, $1=$ not at all effortful to $9=$ very effortful). The two items were highly correlated for both options $(r \mathrm{~s}>.53)$ so we computed scales based on the means for both options. A pairwise $t$-test showed a significant difference, $t(18)=2.17, p<.05$, indicating that participants judged the "visit another website" option as more demanding of time and effort compared the "try again later" option $(M=5.65, S D=1.91$ and $M=4.29, S D=2.14$, respectively).

${ }^{2}$ We analyzed whether the time participants specified in their implementation intention corresponded with the time they actually visited the website in all three experiments. Of the participants who specified a specific date, time or occasion and so we could verify correspondence between the plan and their actual behavior, we found that correspondence rates were $78 \%, 73 \%$ and $69 \%$ in Experiments 1-3, respectively. These findings are in line with previous results (e.g., Sheeran \& Orbell, 2000; Sheeran \& Silverman, 2003). For Experiment 1, we checked whether participants' subsequent attempts to reach the goal made use of the cues that they had specified in the implementation intention geared at initiating goal striving. There was no evidence that this was the case (e.g., participants did not revisit the website at the same time the next day).
} 
Table 3

Type of response of goal intention participants and implementation intention participants

\begin{tabular}{lcc}
\hline Type of response & $\begin{array}{c}\text { Goal intention } \\
n(\%)\end{array}$ & $\begin{array}{c}\text { Implementation } \\
\text { intention } n(\%)\end{array}$ \\
\hline No visit & $33(64.7)$ & $20(39.2)$ \\
Web visit only & $10(19.6)$ & $9(17.6)$ \\
Web visit and e-mail & $8(15.7)$ & $22(43.1)$ \\
Total & $51(100)$ & $51(100)$ \\
\hline
\end{tabular}

Note: $\chi^{2}(2, N=102)=9.76, p<.01$.

8 out of 18 sent us the questionnaire by e-mail (44.4\%). Of the visitors in the implementation intention condition, 22 out 31 returned the questionnaire by e-mail $(71 \%)$. This difference was significant after one-sided testing, $\chi^{2}(1$, $N=49)=3.76, p=.03$ (see Table 3 ).

\section{General discussion}

Three experiments examined whether implementation intention formation promotes both (a) initial striving to reach a goal, and (b) continued goal striving following blockage of the initial attempt. Consistent with previous research, participants who formed implementation intentions were more likely to initiate action compared to participants who formed mere goal intentions (in all three experiments). We also obtained new findings indicating that if-then planning enhanced subsequent goal striving - even though the implementation intention was designed solely to facilitate action initiation (and not repeated attempts to reach the goal). Experiment 1 demonstrated that implementation intention formation increases the likelihood that participants will engage in subsequent goal striving (i.e., more frequent attempts to reach the goal). Experiment 2 showed that forming an implementation intention helps to ensure that a repeated attempt to realize one's intention is acted out as intensively as at the first attempt (i.e., no diminution in the quality of goal striving). A third experiment provided evidence that implementations intentions do not engender rigid repetition of behavior when it is wiser to adopt a different behavior to reach a goal. After experiencing blockage of an initial attempt, participants who formed implementation intentions readily pursued a suggested alternative route to goal attainment - even though the alternative route required greater effort compared to the route in the initial attempt. Taken together, these experiments suggest that forming implementation intentions leads to more resolute and constant goal striving. When confronted with an unexpected barrier, people without an if-then plan are less inclined to try again, and if they do so, then their efforts tend to decrease. People who form implementation intentions, on the other hand, appear to tenaciously strive to reach their goal even after they encounter an unexpected barrier.

Our interpretation of these effects is that forming an implementation intention that specifies how one will strive for a goal conserves self-regulatory capacity for future goal striving, in much the same way that implementation intention formation has been found to conserve cognitive capacity. For instance, Brandstätter, Lengfelder, and Gollwitzer (2001, Experiment 4) showed that participants who formed implementation intentions about how to respond on a primary task not only performed better on that task than did control participants, but they also exhibited a training effect on a secondary task. That is, implementation intention formation released cognitive capacity that could be used to improve participants' responding to the secondary task (p. 956). It seems possible therefore that forming an implementation intention might not only enhance initial attempts to reach the goal, but leaves self-regulatory resources intact so that these resources can be used, if needed, for subsequent goal striving.

In the present experiments, we assumed that blocking participants' initial attempts to reach a goal would deplete self-regulatory resources and thus reduce the likelihood that participants would engage in subsequent attempts to reach the goal (Baumeister et al., 1998; Muraven \& Baumeister, 2000). Consistent with this idea, control participants in our experiments exhibited reduced goal striving (e.g., fewer subsequent attempts, reduced quality of attempts) in the wake of blockage. Participants who formed implementation intentions, however, should not have needed to draw upon self-regulatory strength during their initial attempt to reach the goal. This is because implementation intention formation delegates control of behavior from the self to specified situational cues (i.e., participants' specifications of when and where they would visit the website). Evidence indicates that plan formation serves to heighten cue accessibility (making it likely that the pre-selected opportunity will not be missed) and forges a strong mental link between the specified cue and the intended response (Webb \& Sheeran, 2007, in press). Because the cue and response are strongly associated, as soon as the cue is encountered, action is initiated automatically (i.e., immediately, efficiently, and without the need for conscious intent; see review by Gollwitzer \& Sheeran, 2006). Thus, forming an implementation intention switches action control from a conscious, effortful mode that draws upon self-regulatory strength (action control by goal intentions) to stimulus control of behavior (action control by implementation intentions). Stimulus control of behavior does not rely on self-regulatory resources, which means that these resources are available for subsequent goal striving among participants who formed implementation intentions.

An alternative interpretation of the present findings might be that implementation intention formation served to increase participants' goal intentions or self-efficacy. The idea is that planning out how to strive for the goal could increase one's commitment to, or confidence about, attaining that goal. Although this hypothesis seems plausible, evidence from a recent meta-analysis does not appear to support it (Webb \& Sheeran, in press). Findings showed 
that forming implementation intentions did not increase goal intention or self-efficacy scores (a) compared to noimplementation-intention control conditions, or (b) before versus after plan formation (in 44 and 22 tests of goal intentions and self-efficacy, respectively). Because implementation intention formation has only small and non-significant effects on goal intentions and self-efficacy, whereas several studies indicate that implementation intentions enhance cue accessibility, strengthen cue-response links and produce swift, effortless action initiation (e.g., Gollwitzer \& Sheeran, 2006; Webb \& Sheeran, 2007, in press), delegation of action control to situational cues would seem to better explain the implementation intention effects obtained here than does changes in deliberative variables (goal intentions, self-efficacy).

In sum, the present experiments add to the substantial literature indicating that people are more likely to initiate goal striving when they form implementation intentions. The present findings also provide novel evidence that planning out how to pursue one's goal enhances subsequent goal striving when unexpected barriers are encountered. In the wake of goal blockage, people who form implementation intentions make more frequent, higher quality, and more strenuous efforts to reach their goal compared to people who form mere goal intentions. Implementation intention formation appears to conserve self-regulatory resources so that even when one's path is blocked, one is in a good position to try to overcome the blockage or find a new path. It seems that if-then planning helps one strive, and if need be, strive tenaciously.

\section{References}

Aarts, H., \& Dijksterhuis, A. (2000). Habit as knowledge structures: Automaticity in goal-directed behavior. Journal of Personality and Social Psychology, 78, 53-63.

Aarts, H., Dijksterhuis, A., \& Midden, C. (1999). To plan or not to plan: Goal achievement or interrupting the performance of mundane behaviors. European Journal of Social Psychology, 29, 971-979.

Bagozzi, R. P., \& Yi, Y. (1989). The degree of intention formation as a moderator of the attitude-behavior relationship. Social Psychology Quarterly, 52, 266-279.

Baumeister, R. F., Bratslavsky, E., Muraven, M., \& Tice, D. M. (1998). Ego depletion: Is the active self a limited resource? Journal of Personality and Social Psychology, 74, 1252-1265.

Brandstätter, V., Lengfelder, A., \& Gollwitzer, P. M. (2001). Implementation intentions and efficient action initiation. Journal of Personality and Social Psychology, 81, 946-960.

Chapman, J., Armitage, C. J., \& Norman, P. (in press). Comparing implementation intention interventions in relation to young adults' intake of fruit and vegetables. Psychology and Health.

DiBonaventura, M. D., \& Chapman, G. B. (2005). Moderators of the intention-behavior relationship in influenza vaccinations: Intention stability and unforeseen barriers. Psychology and Health, 20, 761-774.
Gibbons, F. X., Gerrard, M., Blanton, H., \& Russell, D. W. (1998). Reasoned action and social reaction: Willingness and intention as independent predictors of health risk. Journal of Personality and Social Psychology, 74, 1164-1180.

Gollwitzer, P. M. (1993). Goal achievement: The role of intentions. In W. Stroebe \& M. Hewstone (Eds.). European review of social psychology (Vol. 4, pp. 141-185). New York: Wiley.

Gollwitzer, P. M. (1999). Implementation intentions: Strong effect of simple plans. American Psychologist, 54, 493-503.

Gollwitzer, P. M., Jaudas, A., Parks, E., \& Sheeran, P. (2008). Flexible tenacity in goal pursuit. In J. Shah \& W. Gardner (Eds.), Handbook of motivation science (pp. 325-341). New York: Guilford.

Gollwitzer, P. M., \& Schaal, B. (1998). Metacognition in action: The importance of implementation intentions. Personality and Social Psychology Review, 2, 124-136.

Gollwitzer, P. M., \& Sheeran, P. (2006). Implementation intentions and goal achievements: A meta-analysis of its effects and processes. In M. P. Zanna (Ed.). Advances in experimental social psychology (Vol. 38, pp. 69-119). New York: Academic Press.

Muraven, M., \& Baumeister, R. F. (2000). Self-regulation and depletion of limited resources: Does self-control resemble a muscle? Psychological Bulletin, 126, 247-259.

Oettingen, G., Hönig, G., \& Gollwitzer, P. M. (2000). Effective selfregulation of goal-attainment. International Journal of Educational Research, 33, 705-732.

Ouellette, J. A., \& Wood, W. (1998). Habit and intention in everyday life: The multiple processes by which past behavior predicts future behavior. Psychological Bulletin, 124, 54-74.

Schmeichel, B. J., \& Baumeister, R. F. (2004). Self-regulatory strength. In R. F. Baumeister \& K. D. Vohs (Eds.), Handbook of self-regulation: Research, theory, and applications (pp. 84-98). New York: Guilford Press.

Sheeran, P. (2002). Intention-behavior relations: A conceptual and empirical review. In W. Stroebe \& M. Hewstone (Eds.). European review of social psychology (Vol. 12, pp. 1-30). New York: Wiley.

Sheeran, P., \& Orbell, S. (2000). Using implementation intentions to increase attendance for cervical cancer screening. Health Psychology, 19, 283-289.

Sheeran, P., \& Silverman, M. (2003). Evaluation of three interventions to promote workplace health and safety: Evidence for the utility of implementation intentions. Social Science and Medicine, 56, 2153-2163.

Sheeran, P., Trafimow, D., \& Armitage, C. J. (2003). Predicting behavior from perceived behavioral control: Tests of the accuracy assumption of the theory of planned behavior. British Journal of Social Psychology, 42, 393-410.

Triandis, H. C. (1980). Values, attitudes, and interpersonal behavior. In H. E. Howe, Jr \& M. M. Page (Eds.). Nebraska symposium on motivation: Vol. 27. Beliefs, attitudes and values (pp. 195-259). Lincoln: University of Nebraska Press.

Webb, T. L., \& Sheeran, P. (2003). Can implementation intentions help to overcome ego-depletion? Journal of Experimental Social Psychology, 39, 279-286.

Webb, T. L., \& Sheeran, P. (2007). How do implementation intentions promote goal attainment? A test of component processes. Journal of Experimental Social Psychology, 43, 295-302.

Webb, T. L., \& Sheeran, P. (in press). Mechanisms of implementation intention effects: The role of intention, self-efficacy, and accessibility of plan components. British Journal of Social Psychology. 